\title{
Glucose lowers the threshold for human aortic vascular smooth muscle cell migration: inhibition by protein phosphatase- $2 \mathrm{~A}$
}

\author{
M. Campbell • P. Anderson • E. R. Trimble
}

Received: 5 October 2007 / Accepted: 11 January 2008 / Published online: 14 March 2008

(C) Springer-Verlag 2008

\begin{abstract}
Aims/hypothesis Atherosclerosis, which occurs prematurely in individuals with diabetes, incorporates vascular smooth muscle cell (VSMC) chemotaxis. Glucose, through protein kinase $\mathrm{C}-\beta_{\mathrm{II}}$ signalling, increases chemotaxis to low concentrations of platelet-derived growth factor (PDGF)-BB. In VSMC, a biphasic response in PDGF-beta receptor (PDGF$\beta R$ ) level occurs as PDGF-BB concentrations increase. The purpose of this study was to determine whether increased concentrations of PDGF-BB and raised glucose level had a modulatory effect on the mitogen-activated protein kinase/ extracellular-regulated protein kinase pathway, control of PDGF- $\beta$ R level and chemotaxis.

Methods Cultured aortic VSMC, exposed to normal glucose (NG) $(5 \mathrm{mmol} / \mathrm{l})$ or high glucose $(\mathrm{HG})(25 \mathrm{mmol} / \mathrm{l})$ in the presence of PDGF-BB, were assessed for migration (chemotaxis chamber) or else extracted and immunoblotted.

Results At concentrations of PDGF-BB $<540 \mathrm{pmol} / \mathrm{l}$, HG caused an increase in the level of PDGF- $\beta \mathrm{R}$ in VSMC (immunoblotting) versus NG, an effect that was abrogated by inhibition of aldose reductase or protein kinase C- $\beta_{\mathrm{II}}$. At higher concentrations of PDGF-BB (>540 pmol/1) in $\mathrm{HG}$,
\end{abstract}

Electronic supplementary material The online version of this article (doi:10.1007/s00125-008-0962-7) contains supplementary material, which is available to authorised users.

M. Campbell $(\bowtie) \cdot$ P. Anderson · E. R. Trimble

Diabetes Research Group, Queen's University Belfast,

Grosvenor Road,

Belfast BT12 6BJ, UK

e-mail: malcolm.campbell@qub.ac.uk

M. Campbell • E. R. Trimble

Clinical Biochemistry, The Belfast Hospitals Trust,

Belfast, UK receptor level was reduced but in the presence of aldose reductase or protein kinase $\mathrm{C}-\beta_{\mathrm{II}}$ inhibitors the receptor levels increased. It is known that phosphatases may be activated at high concentrations of growth factors. At high concentrations of PDGF-BB, the protein phosphatase (PP)2A inhibitor, endothall, caused an increase in PDGF- $\beta$ R levels and a loss of biphasicity in receptor levels in HG. At higher concentrations of PDGF-BB in HG, the chemoattractant effect of PDGF-BB was lost (chemotaxis chamber). Under these conditions inhibition of PP2A was associated with a restoration of chemotaxis to high concentrations of PDGF-BB. Conclusion/interpretation The biphasic response in PDGF$\beta R$ level and in chemotaxis to PDGF-BB in HG is due to PP2A activation.

Keywords Atherosclerosis · Diabetes · ERK · Extracellular-regulated protein kinase $\cdot$ PDGF-BB $\cdot$ PKC . Platelet-derived growth factor-BB

\begin{tabular}{ll}
\multicolumn{2}{l}{ Abbreviations } \\
AR & aldose reductase \\
DAG & diacylglycerol \\
ERK & extracellular-regulated protein kinase \\
HG & high glucose \\
MAPK & mitogen-activated protein kinase \\
NG & normal glucose \\
PDGF & platelet-derived growth factor \\
PDGF- $\beta$ R & PDGF beta receptor \\
PIKK & phosphatidylinositol 3-kinase \\
PKC & protein kinase C \\
PLC & phospholipase C \\
PP & protein phosphatase \\
PTP & protein tyrosine phosphatase \\
siRNA & small interfering RNA \\
VSMC & vascular smooth muscle cells
\end{tabular}




\section{Introduction}

Atherosclerosis is a major cause of morbidity and mortality in diabetes [1]. During atheroma formation the levels of plateletderived growth factor (PDGF)-BB, a chemoattractant for vascular smooth muscle cells (VSMC), are raised locally within the subendothelial space $[2,3]$. Since PDGF-BB concentrations are also supraphysiologically raised in diabetes and PDGF-beta receptor (PDGF- $\beta \mathrm{R}$ ) production is increased by glucose [4-6], the importance of PDGF-BB signalling may be increased in VSMC migration and atheroma formation in diabetes.

VSMC chemotaxis to PDGF-BB ( 360 pmol/l) is dependent on activation of phosphatidylinositol 3-kinase (PI3K; $\mathrm{p} 110 \beta$ isoform) and cross-talk between the PI3K and mitogen-activated protein kinase (MAPK) pathways [7]. We have shown that glucose increases Akt and extracellular-regulated protein kinase (ERK) activation levels in the PI3K and MAPK pathways, respectively, and enhances that caused by PDGF-BB; in these conditions MAPK/ERK is downstream of PI3K [7, 8]. Glucose causes increased polyol pathway flux leading to de novo synthesis of diacylglycerol (DAG), which is both a cofactor for protein kinase C (PKC) and a direct activator of MAPK/Ras [8, 9]. In aortic VSMC, DAG-dependent signalling directly augments MAPK/ERK activity through Ras and indirectly by $\mathrm{PKC} \beta_{\mathrm{II}}$ promoting crosstalk between PI3K and MAPK [8].

PDGF-BB-associated ERK activation also stimulates activator protein-1 resulting in $P D G F-\beta R$ (also known as $P D G F R B)$ upregulation [10]. Inhibition of either PI3K or MAPK interrupts receptor upregulation and chemotaxis to $360 \mathrm{pmol} / 1$ PDGF-BB [10, 11]. Interestingly, therapeutic statin concentrations also interrupt these responses by inhibiting MAPK/Ras farnesylation [7, 8].

The elevated PDGF-BB concentrations found in atheromas, mainly released from the cell types involved [12], are associated with a fivefold increase in PDGF-BB transcription in the plaque compared with normal arteries [13]. It has been suggested that the chemoattractant effect on VSMC (saphenous vein-derived) is lost at high PDGF-BB concentrations (glucose concentration not stated) [14]. The activation state of signalling pathways depends on the balance between phosphorylation and dephosphorylation of key molecules. If chemotaxis is lost at higher PDGF-BB concentrations then phosphatases may have inactivated the regulating pathways (PI3K and MAPK). Serine/threonine phosphatases, including protein phosphatase (PP)2A, can dephosphorylate MAPK and $\mathrm{PI} 3 \mathrm{~K}$ pathway proteins $[15,16]$.

It is not known whether PP2A activity alters in response to glucose and/or PDGF-BB in VSMC. If PP2A activation is glucose-dependent, then diabetic therapies targeting glucosedependent signalling may leave ERK activity unopposed in elevated PDGF-BB conditions and so potentiate migration (a key event in atheroma formation).
Therefore the aim of the present study was to determine the effects of glucose on PDGF-BB signalling and on the deactivation of signalling pathways involved in human aortic VSMC chemotaxis.

\section{Methods}

For an expanded Methods section, please see Electronic supplementary material (ESM).

Materials Chemicals and antibodies were commercially available except LY379196 (gift from Eli Lilly, Indianapolis, IN, USA) and sorbinil (gift from Pfizer, New York, USA).

Cell culture Explanted human aortic VSMC, obtained with consent from transplant donors, were cultured, in normal glucose (NG; 5 mmol/l D-glucose) and 10\% FCS conditions as described $[11,17]$.

Treatments Unless otherwise stated, cells (passage 3) were washed (serum-free medium, three times) and set up for $24 \mathrm{~h}$ in NG or high glucose (HG) $(\mathrm{NG}+20 \mathrm{mmol} / \mathrm{l} \mathrm{D}$-glucose) in basal conditions $(0.5 \% \mathrm{BSA})$ or in the presence of 36 to $3,600 \mathrm{pmol} / 1 \mathrm{PDGF}-\mathrm{BB} \pm$ inhibitors. Inhibitors were used at concentrations effective in VSMC or were titrated for effect using kinase assays [8, 11, 18-22]. Cells were not serumstarved during these experiments, since this intervention upregulates receptors and potentiates migration to reduced growth factor levels [23, 24]. Treatment did not affect cell viability or proliferation during these experiments but glucose decreased marginally (see ESM, Methods, Treatment effects on cell viability, glucose utilisation and proliferation).

Microinjection Cells (20,000) were seeded in Petri dishes containing etched coverslips as described [8]. All cells within the etched area $(2 \times 2 \mathrm{~mm})$ were microinjected (InjectMan; Eppendorf, Hamburg, Germany) $24 \mathrm{~h}$ later with control (non-specific $\mathrm{IgG}$ ) antibody $(0.1 \mathrm{mg} / \mathrm{ml})$ without/with affinity-purified specific antibodies $(0.1 \mathrm{mg} / \mathrm{ml})$ or small interfering (si)RNA (100 nmol/l) and rested $(2 \mathrm{~h})$ before treatments commenced.

Immunoblotting After treatment, lysate extraction (phosphoprotective buffer), protein concentration determination, immunoprecipitation, western blot and chemiluminescence measurements (densitometry) were done as described [11]. ERK and/or Coomassie Blue-staining of membranes were used as loading controls.

Chemotaxis Cells on coverslips were observed (during the treatment period) in stable PDGF-BB gradients in the Dunn 
chamber (Weber Scientific International, Teddington, UK) in various glucose conditions without/with exposure to pharmacological agents or after microinjection. Pools of cells derived from individual donors produced a consistent migratory response at early passage; therefore, individual experiments were defined by donor source. Cell movement was tracked using image capture software (Metamorph 6.1; Universal Imaging Corporation, West Chester, PA, USA) connected to an IX51 Olympus microscope $(\times 10$ objective; Olympus, Tokyo, Japan). Cell movement was assessed as described [11, $22,25]$. In the absence of a chemoattractant gradient, cells move randomly (net percentage of cell migration is approximately $0 \%$ ). The Rayleigh test is employed to separate out unidirectional movement (i.e. directly towards the growth factor source) from general cellular migration.

Immunofluorescence After treatment, cells on coverslips were fixed, permeabilised and actin localised as described [11]. For localisation of other proteins, the antibody (1:200) was coincubated with phalloidin then FITC-conjugated secondary antibody added $(1 \mathrm{~h})$. Confocal laser-scanning microscopy (Micro Radiance; Bio-Rad, Hercules, CA, USA) was used for imaging and acquiring semi-quantitative measurements (inbuilt software) of masked slides. Results are presented as mean target protein signal for $n>30$ cells from each of more than three independent experiments (with local background subtraction) relative to the equivalent actin signal.

Kinase assays MAPK, Akt (both Cell Signaling Technology, Beverly, MA, USA) and PP2A (Upstate, Charlottesville, VA, USA) assay kits were used according to the manufacturers' instructions. The PKC $\beta_{\text {II }}$ activity assay (PepTag; Promega, Madison, WI, USA) was carried out with those modifications described [8].

Statistics When relevant ANOVA and Fisher's LSD was employed. Data are presented as mean \pm SEM with $p<0.05$ considered statistically significant.

Note that results for migrating cell percentages refer to the net percentage of cells moving in the direction of the PDGFBB: a result of $0 \%$ indicates no net migration (as many cells move towards PDGF-BB as away from it). To detect significant chemotaxis (unidirectional movement) the Rayleigh test for unimodal clustering of directions was used: $p<$ 0.01 was chosen as the criterion for rejecting the null hypothesis of random directionality [7, 11].

\section{Results}

$P D G F-B B$ and glucose effects on PDGF- $\beta R$ protein level We previously demonstrated that raising glucose from normal fasting level $(5 \mathrm{mmol} / \mathrm{l})$ to $25 \mathrm{mmol} / \mathrm{l}$ increases PDGF$\beta R$ levels in aortic VSMC exposed to $360 \mathrm{pmol} / 1$ PDGF-BB concentrations [7, 11].

To determine whether human aortic VSMC demonstrate a biphasic receptor response and identify how glucose modifies this, cells were exposed to basal conditions $(0.5 \%$ BSA) or increasing PDGF-BB concentrations in normal or raised glucose conditions. Total receptor protein level was determined (Fig. 1a,b). At NG (5 mmol/1 D-glucose), PDGF-BB caused a dose-dependent increase in PDGF- $\beta$ R level until $1,080 \mathrm{pmol} / 1$ PDGF-BB; above this concentration the receptor level fell. By contrast at HG $(25 \mathrm{mmol} / \mathrm{l} \mathrm{D}$-glucose, $24 \mathrm{~h}$ ), the maximum receptor level occurred at a PDGF-BB concentration of $540 \mathrm{pmol} / \mathrm{l}$, above which the receptor level fell sharply. At concentrations $\leq 720 \mathrm{pmol} / \mathrm{l}$ PDGF-BB, the receptor level was greater in HG than in NG. The HG effect was not due to an osmotic effect of glucose since the nonmetabolisable analogue L-glucose (NG plus $20 \mathrm{mmol} / \mathrm{l}$ L-glucose, $24 \mathrm{~h}$ ) was similar to NG. An intermediate D-glucose concentration $(10 \mathrm{mmol} / \mathrm{l})$ also had maximum receptor levels at $540 \mathrm{pmol} / 1$ (mean 2.6 \pm 0.15 -fold above basal; $n=4$, not shown).

The results clearly show a biphasic PDGF- $\beta$ R response to PDGF-BB for aortic VSMC. Glucose caused a left-shift in the biphasic response to PDGF-BB and increased the maximum receptor level. Similar responses to glucose and PDGF-BB were found for PDGF- $\beta R$ level at the cell surface, where PDGF-BB binding occurs (assessed by cell membrane immunoblotting and immunofluorescence of non-permeabilised cells) and in mRNA level (RT-PCR; see ESM Figs 1 and 2a,b).

PDGF-BB and glucose effects on ERK and Akt phosphorylation PDGF- $\beta$ R regulation in $\mathrm{HG}$ at $360 \mathrm{pmol} / \mathrm{l}$ PDGF-BB concentrations depends on MAPK/ERK pathway signalling with crosstalk from the PI3K/Akt pathway [7]. As was found for the receptor, phospho-ERK1/2 (Fig. 1c,d) and to a lesser degree phospho-Akt (Fig. 1e,f) showed biphasic responses to PDGF-BB, whereas the total protein levels remained constant. Glucose increased the maximum phosphorylation level and left-shifted the curves for phospho-ERK and phospho-Akt. ERK signals to the transcription factor, activator protein-1 (c-fos and c-Jun), which has a $P D G F$ $\beta R$ gene promoter binding site $[10,26]$. In assays employing nuclear extracts c-fos and c-Jun binding to an immobilised oligonucleotide reflected the changes in PDGF- $\beta$ R level under similar conditions (ESM Fig. 2c-e).

$P D G F-B B$ and glucose effects on chemotaxis The major functional VSMC response in atherosclerosis is migration into the plaque. Figure $1 \mathrm{~g}$ shows a biphasic response for PDGF-BB-induced chemotaxis. Glucose caused a left-shift in the response with chemotaxis being detected in NG (or 
Fig. 1 Effect of PDGF-BB and glucose $(24 \mathrm{~h})$ on PDGF- $\beta \mathrm{R}$ production $(\mathbf{a}, \mathbf{b})$, ERK phosphorylation (c, d), Akt phosphorylation $(\mathbf{e}, \mathbf{f})$ and chemotaxis (g). a-f Relative densitometric results for PDGF- $\beta$ R protein (a), phospho-ERK (c) and phospho-Akt (e), respectively (mean \pm SEM), following immunoprecipitation and western blotting $(\mathbf{b}, \mathbf{d}, \mathbf{f})$ in VSMC (passage 3) lysates. VSMC had been previously incubated in NG (5 mmol/1 D-glucose), HG (NG plus $20 \mathrm{mmol} / \mathrm{l} \mathrm{D}$-glucose, $25 \mathrm{mmol} / \mathrm{l} \mathrm{D}$-glucose) or NG plus $20 \mathrm{mmol} / 1 \mathrm{~L}$-glucose (LG; osmotic control) under basal conditions (B; $0.5 \% \mathrm{BSA})$ or 36-3600 pmol/1 (1-100 ng/ml) PDGF-BB for $24 \mathrm{~h}(n=30$ independent experiments). Total ERK and Akt protein (d, f) (representative blots) did not alter and were employed as loading controls.

g Corresponding Dunn chemotaxis results. Percentages represent net percentage of observed cells $(>98 \%$ viability for each condition) that moved $>30 \mu \mathrm{m}$ up the PDGF-BB concentration gradient $(n>30$ cells tracked from each of five independent experiments). Grey squares/line, $\mathrm{NG}$; black triangles/continuous line, HG; black circles/dotted line, LG. Analysis: ANOVA. ${ }^{*} p<0.05$ and $* * p<0.01$ vs bas$\mathrm{al} ;{ }^{\dagger} p<0.05$ and ${ }^{\dagger \dagger} p<0.01$ vs $\mathrm{NG}$ (and LG); ${ }^{\sharp} p<0.01$ in Rayleigh test for unidirectional movement $=$ significant chemotaxis a

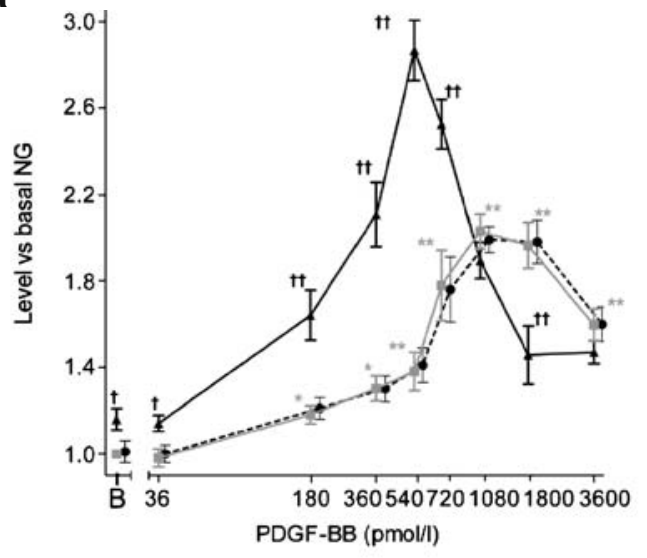

b
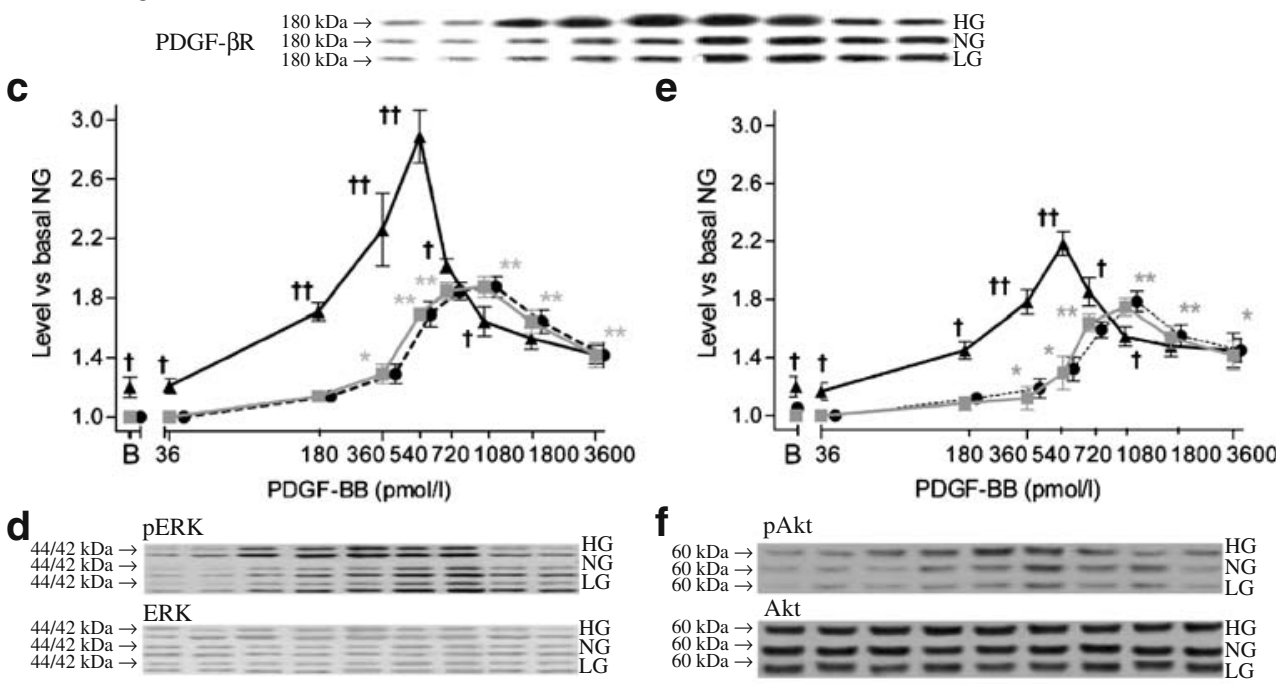

$\mathbf{f}_{60 \mathrm{kDa} \rightarrow} \mathrm{pAkt}$ $60 \mathrm{kDa} \rightarrow \square=- \pm= \pm=-{ }_{\mathrm{NG}}^{\mathrm{HG}}$
$60 \mathrm{kDa} \rightarrow$ $60 \mathrm{kDa} \rightarrow \mathrm{Akt}$ 60 kDa $\rightarrow=-2=-2=-\mathrm{HG}$ $\underset{60 \mathrm{kDa} \rightarrow}{60 \mathrm{kDa} \rightarrow}= \pm= \pm= \pm= \pm$

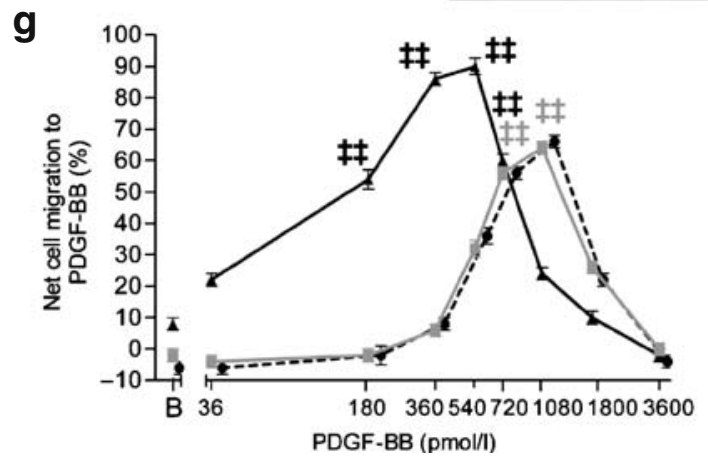

$\mathrm{NG}+20 \mathrm{mmol} / \mathrm{l} \mathrm{L}$-glucose) between 720-1,080 pmol/1 PDGF$\mathrm{BB}$, and in $\mathrm{HG}$ between $180-720 \mathrm{pmol} / \mathrm{l}$. At 1,800 3,600 pmol/1 PDGF-BB, no significant net migration occurred at either glucose level. In atheromas, PDGF-BB levels may not match those found to induce migration in Fig. 1g; other factors may modify migration in vivo $[2,3,27]$.

Chemotaxis experiments were run for $18 \mathrm{~h}$, and the above relate to the condition at the end of that period. However, cell movement recording allows the results to be interrogated at various time intervals. At $6 \mathrm{~h}$ the PDGF-BB concentrations causing chemotaxis in NG and HG were the same as at $18 \mathrm{~h}$ (not shown).
These results indicate that phospho-ERK, phospho-Akt and their targets PDGF- $\beta$ R protein levels and chemotaxis follow similar biphasic response patterns to PDGF-BB concentrations as glucose changes.

$P D G F-\beta R$ level control in the presence of PDGF-BB and glucose Since we have previously shown that MAPK/Ras, $\mathrm{PI} 3 \mathrm{~K}, \mathrm{PKC} \beta_{\mathrm{II}}$ and aldose reductase (AR; the rate-limiting polyol pathway enzyme) control receptor level, phosphoERK and chemotaxis at $360 \mathrm{pmol} / \mathrm{l}$ PDGF-BB [7, 8], these pathways were investigated here at higher PDGF-BB concentrations (Fig. 2). 
Fig. 2 Effect of second messenger pathway inhibitors on PDGF- $\beta$ R protein $(\mathbf{a}, \mathbf{c})$, phospho-ERK $(\mathbf{b}, \mathbf{c})$ and chemotaxis (d). Total PDGF- $\beta$ R protein (a) and phospho-ERK (b) for immunoblotted VSMC lysates set up in similar conditions as Fig. 1, without/with inhibitors ( $n=8$ independent experiments); densitometric results vs total ERK (c). d Corresponding Dunn chamber chemotaxis results ( $>97 \%$ viability; $n>30$ cells from each of five independent experiments). Solvent controls: inhibitors all dissolved in DMSO except LY379196, methanol $(80 \%)$; final concentrations $<1.0 \mu \mathrm{l} / \mathrm{ml}$. Inhibitors: PDGF- $\beta R$ kinase (K; AG1296; $10 \mathrm{mmol} / \mathrm{l}$ ), MAPK/Ras isoprenylation (farnesyltransferase inhibitor [FTI]: $2 \mathrm{nmol} / \mathrm{l}$; pravastatin: $100 \mathrm{nmol} / \mathrm{l}$ ), MAPK/MAPK kinase (PD98059: $10 \mu \mathrm{mol} / \mathrm{l})$, PI3K (LY294002: $10 \mu \mathrm{mol} / \mathrm{l}$; wortmannin: $10 \mathrm{nmol} / \mathrm{l})$, general PKC (calphostin C: $50 \mathrm{nmol} / \mathrm{l}$ ), PKC $_{\beta \text { II }}(L Y 379196: 200 \mathrm{nmol} / \mathrm{l})$ and AR (alrestatin: $20 \mu \mathrm{mol} / \mathrm{l}$; sorbinil: $500 \mu \mathrm{mol} / 1)$. Grey bars, NG; black bars, HG. Analysis: ANOVA. ${ }^{*} p<0.05$ and $* * p<$ 0.01 vs basal (B); ${ }^{\dagger} p<0.05$ and ${ }^{\dagger} p<0.01$ vs relevant (same glucose level and same PDGF-BB concentration) solvent control; ${ }^{4} p<0.01$ in Rayleigh test for unidirectional movement $=$ significant chemotaxis a

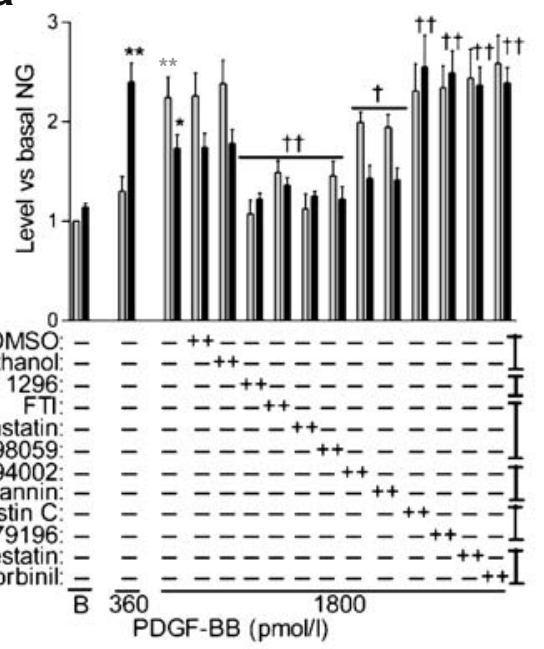

b

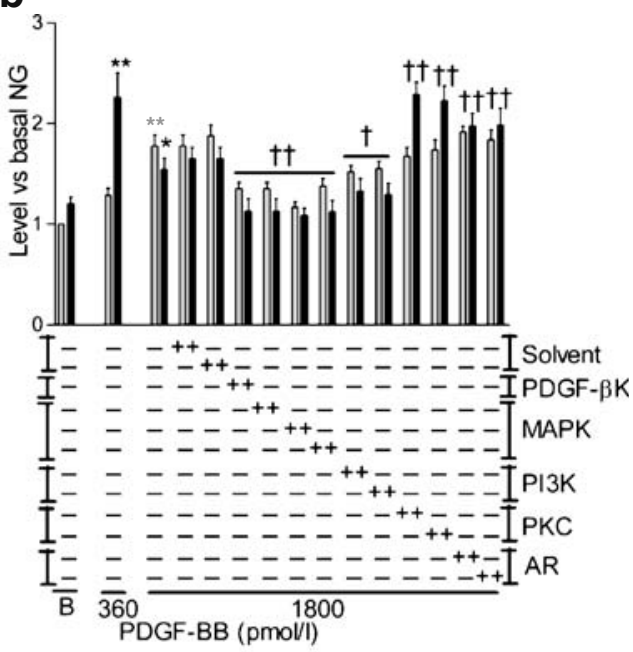

C
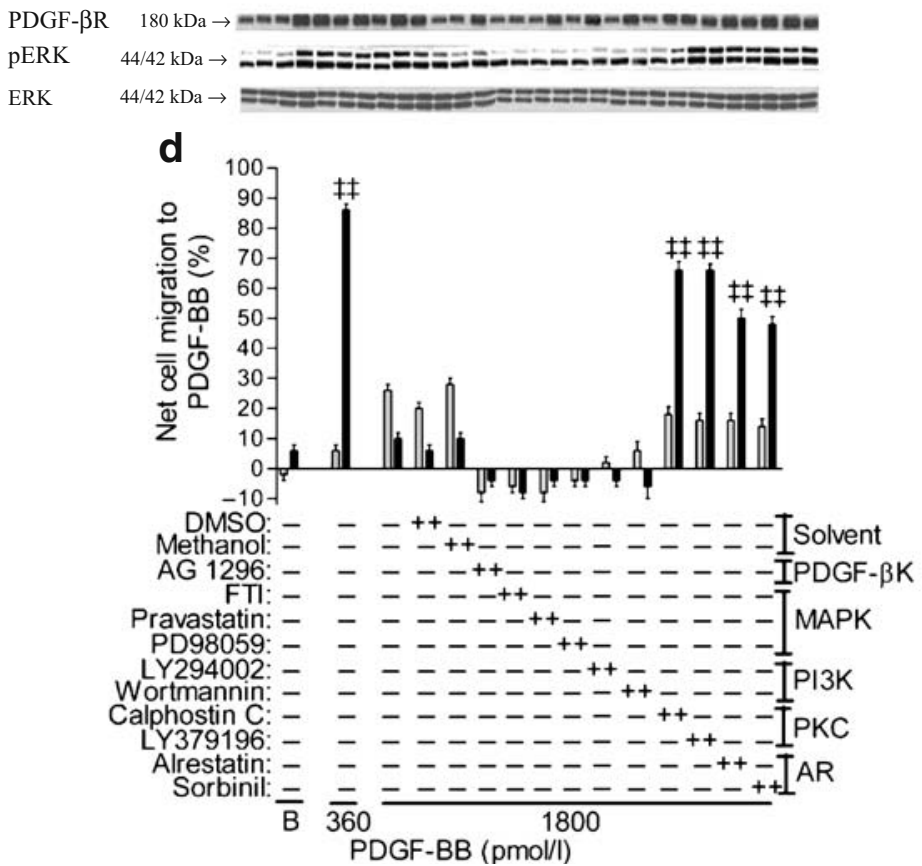

Experiments carried out to identify how total receptor level was reduced in the presence of elevated PDGF-BB concentrations in NG and $\mathrm{HG}$ employed chemical inhibitors (Fig. 2a,c). Solvent controls did not alter receptor level. In the presence of PDGF-BB 1,800 pmol/l, PDGF- $\beta$ R kinase inhibition (AG1296) reduced the receptor to basal level in both NG and HG, showing that PDGF- $\beta$ R activation is a controlling factor of receptor protein level. MAPK inhibition at the level of Ras (farnesyltransferase inhibitor and pravastatin: non-specific inhibitors of Ras-dependent signalling in aortic VSMC) $[7,8]$ or MAPK kinase 1/2 (PD98059) as well as PI3K inhibition (LY294002 and wortmannin; inhibitors with different profiles) reduced receptor level in $1,800 \mathrm{pmol} / 1$ PDGF-BB at both glucose levels.
Glucose has a major effect on PDGF- $\beta$ R level in response to PDGF-BB. Since HG increases polyol pathway flux and activates $\mathrm{PKC} \beta_{\mathrm{II}}[8,28]$, the influence of this pathway and $\mathrm{PKC} \beta_{\text {II }}$ on receptor level were investigated. A major finding was that at the higher PDGF-BB concentration $(1,800 \mathrm{pmol} / \mathrm{l})$ in $\mathrm{HG}, \mathrm{PKC}$ inhibitors (calphostin C: general PKC inhibitor; or LY379196: $\mathrm{PKC} \beta_{\mathrm{II}^{-}}$-specific inhibitor at $200 \mathrm{nmol} / 1$ [8]) or AR inhibitors (alrestatin and sorbinil) increased receptor levels, eliminating the difference between NG and HG. (It should be noted that at $360 \mathrm{pmol} / \mathrm{l} \mathrm{PDGF}-\mathrm{BB}$ in $\mathrm{HG}, \mathrm{AR} / \mathrm{PKC}$ inhibition decreases PDGF- $\beta$ R receptor level [8].) As expected AR/PKC inhibition had no effect on receptor level in NG.

The results so far show that the biphasic PDGF- $\beta R$ response can be abrogated by $\mathrm{AR} / \mathrm{PKC} \beta_{\mathrm{II}}$ inhibition at high 
PDGF-BB concentrations (1,800 pmol/l) in HG. To see whether $\mathrm{AR} / \mathrm{PKC} \beta_{\mathrm{II}}$ inhibition could also restore phosphoERK under these conditions the following experiments were undertaken.

ERK phosphorylation control in the presence of PDGF-BB and glucose To identify whether the biphasic response in $P D G F-\beta R$ expression occurs above the ERK signalling level, phospho-ERK was assessed under 1,800 pmol/1 PDGF-BB conditions (Fig. 2b). Inhibition of PDGF- $\beta \mathrm{R}$ kinase or MAPK significantly decreased phospho-ERK in NG and HG. PI3K inhibitors also decreased phospho-ERK level in 1,800 pmol/1 PDGF-BB, but to a lesser degree. MAPK inhibitors did not alter phospho-Akt level under these conditions, indicating that PI3K to MAPK crosstalk, present at $360 \mathrm{pmol} / \mathrm{l}$ PDGF-BB concentrations [7], also occurs at 1,800 pmol/1 PDGF-BB (data not shown).

By contrast, PKC inhibition significantly increased phospho-ERK in HG. AR inhibition also significantly increased phospho-ERK in $\mathrm{HG}$, but to a lesser degree. As expected, $\mathrm{AR} / \mathrm{PKC}$ inhibition did not alter phospho-ERK in NG. The contrasting pharmacological inhibitor results for $\mathrm{AR} / \mathrm{PKC}$ were confirmed both by microinjection techniques (ESM Fig. 3a,b; phospho-PKC $\beta_{\text {II }}{ }^{(\text {Ser660) }}$ antibodies or AR siRNA microinjected) and by ERK activity assay (ESM Fig. 3c). These results indicate that ERK activity is reduced by AR/ $\mathrm{PKC} \beta_{\mathrm{II}}$ signalling in $\mathrm{HG}$ at $1,800 \mathrm{pmol} / \mathrm{l} \mathrm{PDGF}-\mathrm{BB}$.

Chemotaxis control in the presence of $P D G F-B B$ and glucose Chemotaxis results (Fig. 2d) were obtained for those conditions investigated in Fig. 2a-c. In $\mathrm{HG}$ $1,800 \mathrm{pmol} / 1$ PDGF-BB, PDGF- $\beta \mathrm{R}$ kinase, MAPK or $\mathrm{PI} 3 \mathrm{~K}$ inhibitors prevented chemotaxis, but $\mathrm{AR} / \mathrm{PKC} \beta_{\mathrm{II}}$ inhibition restored it and its related morphology (including filopodia formation; ESM Fig. 4a). Chemotaxis results from the microinjection experiments noted above confirmed the inhibitor results (ESM Fig. 4b).

These results (Fig. 2) are consistent with the effect of glucose on the biphasic response in PDGF- $\beta$ R and chemotaxis occurring above the level of ERK signalling, with AR/ $\mathrm{PKC} \beta_{\mathrm{II}}$ signalling promoting ERK activation at low PDGFBB levels [8], but contributing to inhibition at high levels.

Activation of $P K C \beta_{I I}$ by $P D G F-B B$ and glucose Since the negative regulation of PDGF- $\beta$ R level, ERK activity and chemotaxis in high PDGF-BB concentrations in $\mathrm{HG}$ was PKC $\beta_{I I}$-dependent (Fig. 2), the control of phospho-PKC $\beta_{\mathrm{II}}$ was investigated next (Fig. 3a,b).

In $\mathrm{NG}$, a small significant reduction in phosphoPKC $\beta_{\text {II }}{ }^{(\text {Ser660) }}$ occurred at high PDGF-BB levels. In $\mathrm{HG}$, in the absence of PDGF-BB, phospho-PKC $\beta_{\text {II }}$ was significantly elevated compared with $\mathrm{NG}$ and rose further (monophasic response) as PDGF-BB concentrations increased.
Pathway inhibitor effects on phospho-PKC $\beta_{\text {II }}$ were next investigated. MAPK and PI3K inhibition had no effect on phospho-PKC $\beta_{\mathrm{II}}$ (Fig. 3c,d), confirming that $\mathrm{PKC} \beta_{\mathrm{II}}$ activation occurs upstream of MAPK and PI3K.

Diacylglycerol (a cofactor for $\mathrm{PKC} \beta_{\mathrm{II}}$ activation) can be generated from two distinct intracellular pools: (1) PDGF$\beta R$ signalling causes phospholipase C (PLC) $\gamma$ activation, which hydrolyses phosphatidylinositol bisphosphate to form DAG (glucose-independent DAG) and inositol 1,4,5triphosphate; and (2) in elevated glucose conditions de novo synthesis of DAG (glucose-dependent DAG) also occurs through an AR-dependent pathway. Inhibition of PDGF- $\beta$ R kinase resulted in a small (significant) phosphoPKC $\beta_{\text {II }}$ decrease in both glucose conditions: since this effect was glucose-independent, inhibition of PLC $\gamma$-signalling was considered to be the probable cause. Indeed PLC $\gamma$ inhibition (U-73122) had a similar effect to PDGF- $\beta$ R kinase inhibition. AR inhibition had no effect in NG but abolished the $\mathrm{HG}$ effect confirming a glucose-dependent response in phospho-PKC $\beta_{\mathrm{II}}$. $\mathrm{PKC} \beta_{\mathrm{II}}$ phosphorylation therefore is receptor/PLC $\gamma$-dependent in $\mathrm{NG}$ and $\mathrm{HG}$; this is augmented by AR-dependence in $\mathrm{HG}$.

The AR effect was confirmed with a PKC $\beta_{\mathrm{II}}$ activity assay (Fig. 3e,f). PKC $\beta_{\mathrm{II}}$ requires membrane binding for full activity [8]. In PDGF-BB 1,800 pmol/1 PKC $\beta_{\text {II }}$ activity in isolated membranes was 2.5-fold greater in $\mathrm{HG}$ than in NG. This effect was blocked by AR inhibition. Cytoplasmic PKC $\beta_{\text {II }}$ activity remained unchanged.

The above results indicated that the glucose-potentiated left-shift in the biphasic response to PDGF-BB was due to negative effects associated with $P K C \beta_{I I}$ signalling in high PDGF-BB concentrations, but the mechanism was unknown. Phosphatases activated in HG, diabetes or atherosclerosis, as well as those known to affect the MAPK and PI3K pathways were investigated to identify putative effectors of the biphasic response.

Phosphatase inhibitor effects on PDGF- $\beta R$ level Total PDGF- $\beta$ R production was assessed (cell lysate immunoblotting) after VSMC were exposed to PP inhibitors (PP1, PPI2; PP2A, endothall and okadaic acid; PP2B, fenvalerate) or protein tyrosine phosphatase (PTP) inhibitors (PTP1B, PTPI; general PTPs, vanadate). In NG, only PTP1B inhibition significantly increased the receptor level at 1,800 pmol/1 PDGF-BB (Fig. 4a,b); in HG PTP1B elicited a similar response, indicating a glucoseindependent effect. However in HG (1,800 pmol/1 PDGFBB), PP2A inhibition significantly augmented PDGF- $\beta$ R level, whereas in NG the effect was minimal (nonsignificant), indicating a glucose-dependent effect.

Phosphatase inhibitor effects on chemotaxis to PDGF$B B$ Matched cells to those investigated (Fig. 4a,b) were 
Fig. 3 Effect of glucose and PDGF-BB on PKC $\beta_{\text {II }}$ phosphorylation. a Relative densitometric results for phospho-PKC $\beta_{\text {II }}^{\text {Ser660 }}$ (mean \pm SEM) for immunoblotted VSMC lysates from cells treated as in Fig. 1 ( $n=30$ independent experiments) or with added inhibitors (c) $(n=8$ independent experiments). b, d Respective immunoblots. Loading control: total ERK protein. e, f PKC $\beta_{\text {II }}$ activity results for alrestatin (cf. a-d) for membranous (e) and cytoplasmic (f) fractions ( $n=4$ independent experiments). Inhibitors: PLC $\gamma$ (U-73122: $5 \mu \mathrm{mol} / \mathrm{l})$ and its negative control (U-73343: $5 \mu \mathrm{mol} / \mathrm{l})$. For other inhibitors and treatment conditions, see Fig. 2. Grey squares/grey line, NG; black triangles/continuous line, $\mathrm{HG}$; black circles/dotted line, $\mathrm{NG}+20 \mathrm{mmol} / \mathrm{l} \mathrm{L}$-glucose (LG); grey bars, NG; black bars, HG. Analysis: ANOVA. ${ }^{*} p<$ 0.05 and $* * p<0.01$ vs basal (B); ${ }^{\dagger \dagger} p<0.01$ vs $\mathrm{NG} ;{ }^{\star} p<0.05$ and $\pm p<0.01$ vs DMSO at same glucose level and PDGF-BB concentration

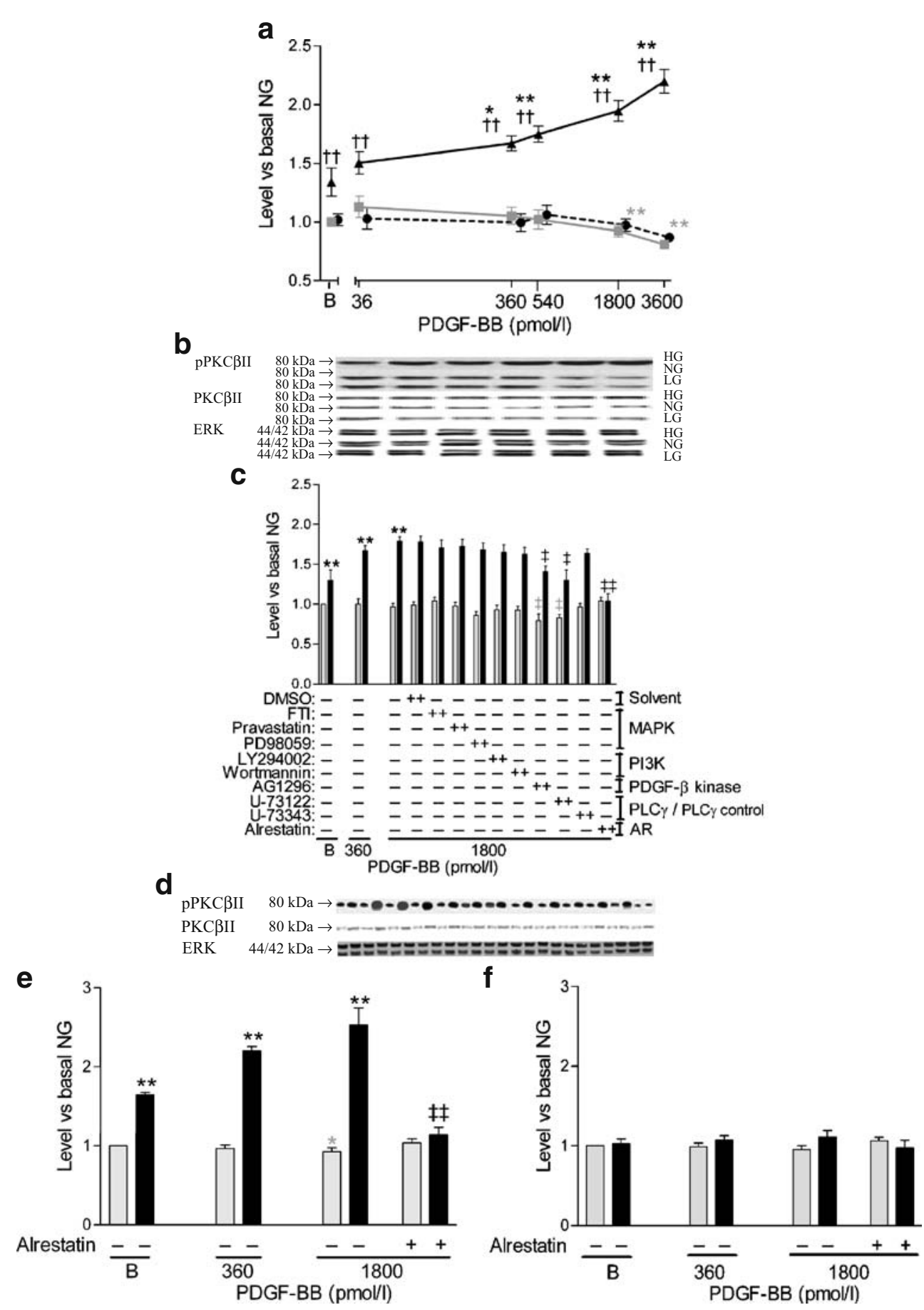

assessed for chemotaxis (Fig. 4c). Although PTP1B inhibition had a small effect in increasing PDGF- $\beta$ R level (Fig. 4a,b), significant chemotaxis was not detected (Fig. 4c; Rayleigh test, $p=0.21$ ). However, the significant increase in receptor numbers in HG due to PP2A inhibition, a known MAPK modulator, was associated with restored chemotaxis; PP2A had little effect in NG.

To confirm the inhibitor results and to exclude a role for MAPK phosphatases (known to be glucose-independent [29]), monoclonal antibody microinjection studies were undertaken
(Fig. 4d). In $360 \mathrm{pmol} / 1$ PDGF-BB, PP2A or PTP1B antibody microinjection had no effect on chemotaxis. At 1,800 pmol/1 PDGF-BB, anti-PTP1B did not restore chemotaxis at either glucose level. Anti-PP2A restored chemotaxis in $\mathrm{HG}$; the effect was specific since antibody preabsorption could not mimic the effect. The MAPK phosphatase antibodies had no significant effect.

Similar results to those shown for antibody microinjection (Fig. 4d) were found with $P P 2 A$ or $P T P 1 B$ siRNA microinjection (not shown). Microinjection of active PTP1B 
peptide $(10 \mathrm{nmol} / \mathrm{l})$ to cells in $\mathrm{HG}$ at $360 \mathrm{pmol} / \mathrm{l}$ or $1,800 \mathrm{pmol} / 1$ PDGF-BB did not significantly alter migration (net cell migration $75 \pm 4$ and $5 \pm 2 \%$ respectively).

The biphasic PDGF- $\beta R$ and chemotaxis responses appear to be due to negative regulation in HG and high PDGF-BB conditions mainly by PP2A activity. The biphasic responses

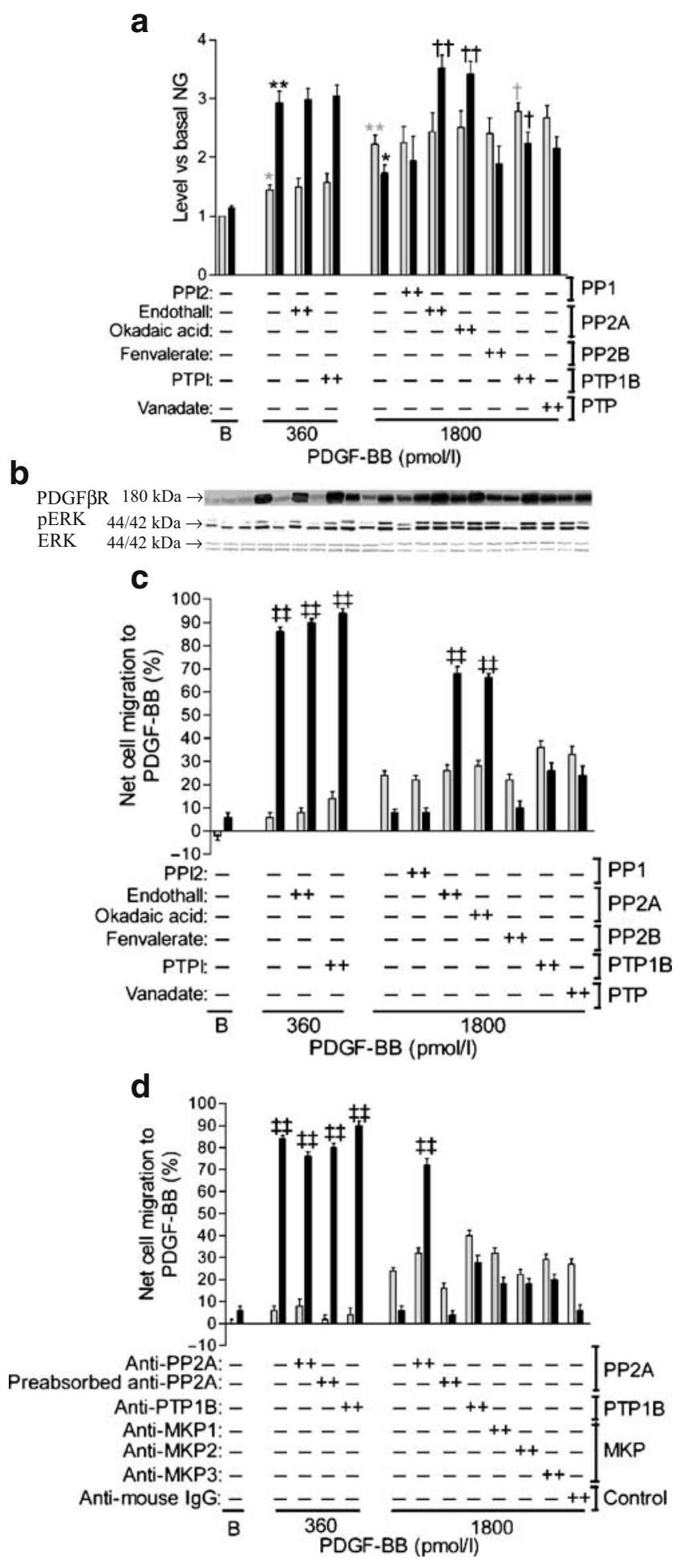

in NG were less dependent on any one phosphatase, with most inhibitors or antibodies having a marginal ability to increase receptor level (significant for PTP1B) or chemotaxis.

Phosphatase inhibitor effects on ERK, Akt and PKC $\beta_{I I}$ activation If $\mathrm{PP} 2 \mathrm{~A}$ critically regulates the biphasic responses noted in this study, then PP2A blockade in HG should have a similar effect on ERK signalling, as with receptor level and chemotaxis. In PDGF-BB $360 \mathrm{pmol} / \mathrm{l}$, neither PP2A nor PTP1B inhibition altered phospho-ERK level in NG or HG (Fig. 5a,b). In PDGF-BB 1,800 pmol/1 and NG, PTP1B inhibition increased phospho-ERK by a small, significant amount; changes due to PP2A inhibition were not significant. In PDGF-BB 1,800 pmol/1 and HG, PTP1B inhibition resulted in a small increase in phospho-ERK, while PP2A inhibition resulted in a marked phosphorylation increase; the phospho-ERK response to PP2A inhibition was matched by an increase in ERK activity (Fig. 5c). ERK activity also increased with PP2A inhibition at PDGF-BB $1,800 \mathrm{pmol} / \mathrm{l}$ in $\mathrm{NG}$, but to a lesser degree than in HG.

Akt also has a biphasic phosphorylation (Fig. 1e,f) and activity (Fig. 5d) profile, but is less affected (fold changes) by PDGF-BB and glucose than ERK. Akt is a PKC $\beta_{\text {II }}$ signalling target involved in crosstalk to MAPK [8] and is a known PP2A target. PP2A inhibition increased Akt signalling in PDGF-BB 1,800 pmol/1 and HG (Fig. 5d), but to a lesser degree than that seen in ERK activity (Fig. 5c).

In similar conditions we investigated the PP2A and PTP1B inhibition effects on PKC $\beta_{\text {II }}$ phosphorylation (Fig. 5e,f) and activity (Fig. 5g,h). PKC $\beta_{\text {II }}$ activation did not depend on PP2A or PTP1B.

Phospho-PP2A: modification by PDGF-BB and glucose Decreased phospho-PP2A $\mathrm{A}^{\mathrm{Ty} 307}$ level is associated with increased PP2A activity [30]. In NG, phospho-PP2A was

Fig. 4 Effect of phosphatase inhibitors on PDGF- $\beta$ R protein and chemotaxis. a Relative densitometric results (mean \pm SEM) and (b) immunoblot respectively for PDGF- $\beta$ R protein in immunoblotted lysates of cells treated as in Fig. 1 plus phosphatase inhibitors $(n=8$ independent experiments). c Corresponding Dunn chamber chemotaxis results $(n>30$ cells tracked from each of five independent experiments). d Confirmatory chemotaxis results (for c) using micro-injected phosphatase antibodies, preabsorbed PP2A antibody (pre-exposed to molar excess of cognate peptide before injection), non-specific antibodies and sham injection. Micro-injected/sham-injected VSMC were rested $(2 \mathrm{~h})$ then placed in the Dunn chemotaxis chamber $(18 \mathrm{~h})$ and tracked $(n>30$ cells tracked from each of four independent experiments). Inhibitors: PP1 (PPI2: $2 \mathrm{nmol} / \mathrm{l}$ ), PP2A (endothall: $90 \mathrm{nmol} / \mathrm{l}$; okadaic acid: $1 \mathrm{nmol} / \mathrm{l}$ ), PP2B (fenvalerate: $2 \mathrm{nmol} / \mathrm{l}$ ), PTP1B (PTPI: $40 \mu \mathrm{mol} / \mathrm{l}$ ) and non-specific PTP (vanadate: $10 \mathrm{mmol} / \mathrm{l}$ ). MKP, MAPK phosphatase. Grey bars, NG; black bars, HG. Analysis: ANOVA. ${ }^{*} p<0.05$ and ${ }^{* *} p<0.01$ vs basal (B); ${ }^{\dagger} p<0.05$ and ${ }^{\dagger \dagger} p<0.01$ vs DMSO at same glucose level and PDGF-BB concentration; ${ }^{\sharp} p<0.01$ in Rayleigh test for unidirectional movement= significant chemotaxis 
Fig. 5 Effect of phosphatase inhibitors on ERK (a-c), Akt (d) and $\mathrm{PKC} \beta_{\mathrm{II}}(\mathbf{e}-\mathbf{h})$ activity. a Relative densitometric results (mean \pm SEM) and respective blot (b) for phospho-ERK in immunoblotted lysates; cells were treated as in Fig. 1 without/with inhibitors $(n=8$ independent experiments). c Confirmatory protein activity results for endothall under similar conditions to those for phospho-ERK (a) ( $n=4$ independent experiments). d Akt activity under conditions of panel $\mathbf{c}(n=4$ independent experiments). e Relative densitometric result and respective blot (f) for phospho-PKC $\beta_{\text {II }}$ matching conditions for ERK (a). g, h Confirmatory $\mathrm{PKC} \beta_{\mathrm{II}}$ activity results for membranous (g) and cytoplasmic (h) fractions, respectively under similar conditions to those for phosphoPKC $\beta_{\text {II }}$ (e) $(n=4$ independent experiments). Inhibitors: see Fig. 4 legend. Grey bars, NG; black bars, HG. Analysis: ANOVA. ${ }^{*} p<0.05$ and $* * p<$ 0.01 vs basal (B); ${ }^{\dagger} p<0.05$ and ${ }^{\dagger} p<0.01$ vs DMSO at same glucose level and PDGF-BB concentration a

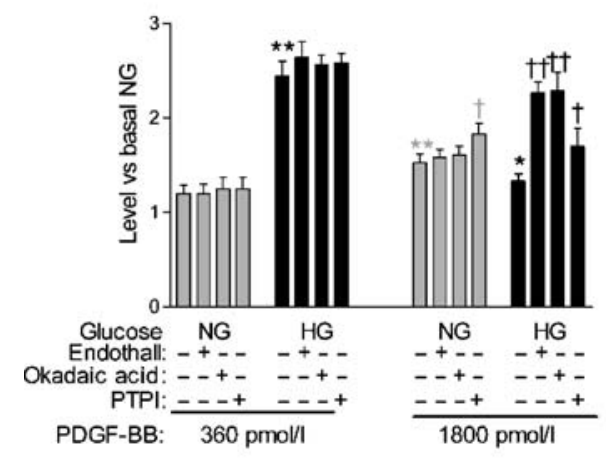

b

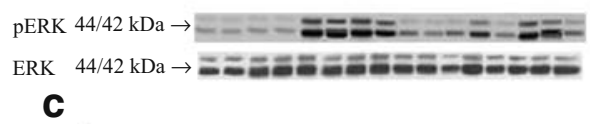

C

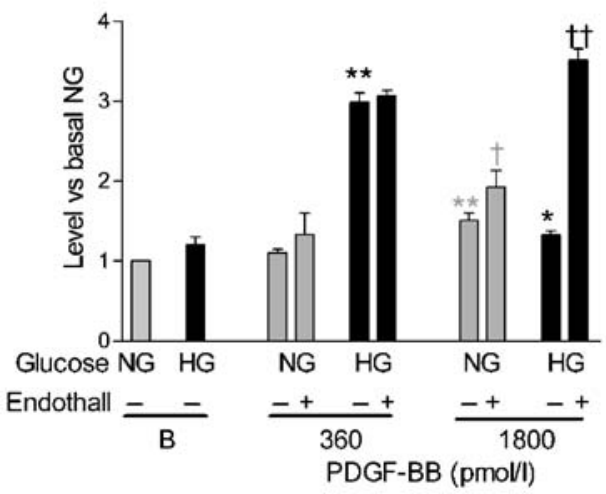

d

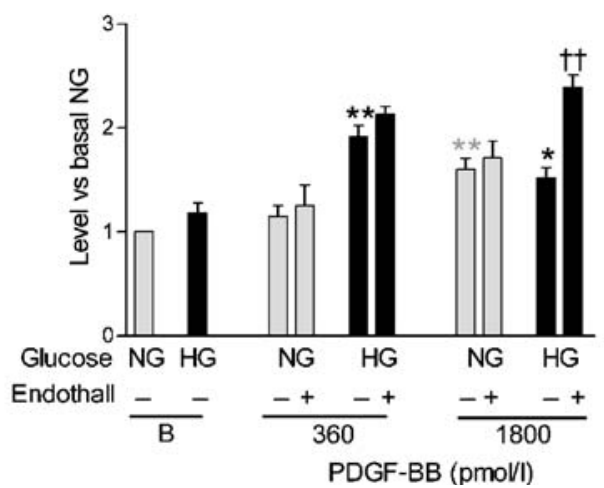

e

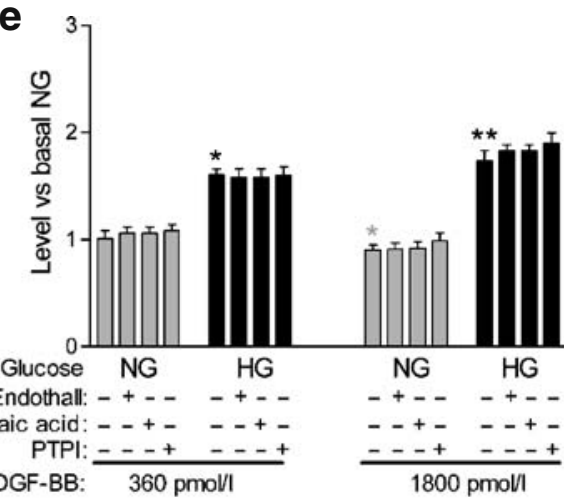

f

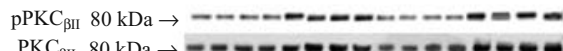

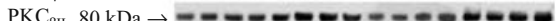

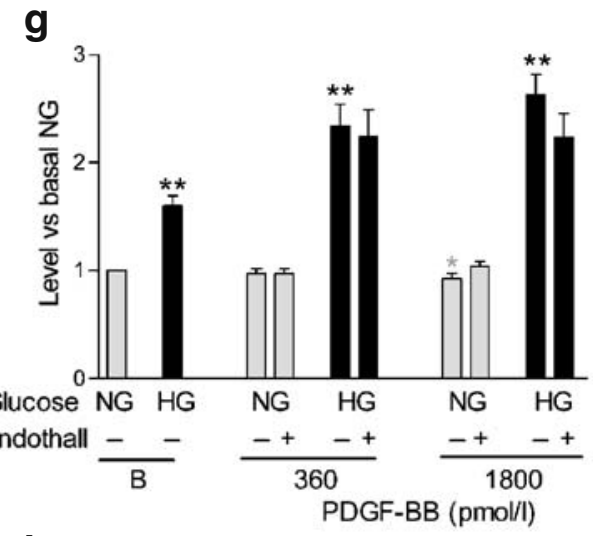

h

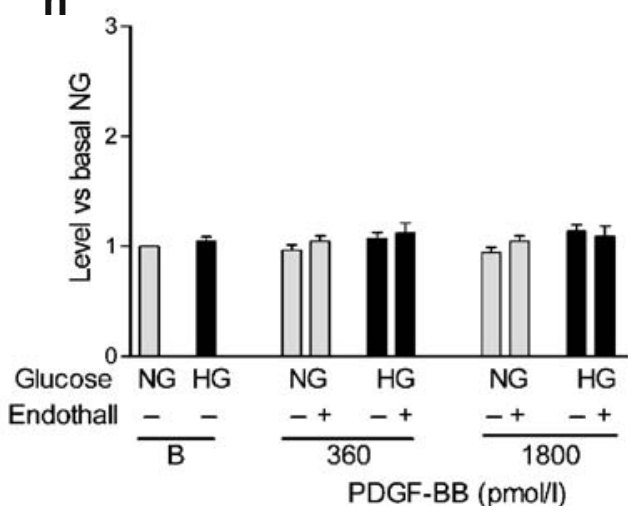

relatively unaltered by PDGF-BB (Fig. 6a,b). By contrast, in HG phospho-PP2A was significantly decreased at PDGFBB concentrations above $540 \mathrm{pmol} / \mathrm{l}$; therefore active PP2A levels increase where $\mathrm{HG}$ and high PDGF-BB concentrations coexist. Total PP2A protein levels remained unchanged throughout.

Phospho-PP2A control in the presence of PDGF-BB and glucose Neither MAPK inhibition by PD98059 (Fig. 6c,d) nor pravastatin (not shown) nor PI3K inhibition altered phospho-PP2A. PKC $\beta_{\mathrm{II}}$ or AR inhibition (Fig. 6e,f) or microinjection of $\mathrm{PKC} \beta_{\mathrm{II}}$ antibody or AR siRNA (not shown) increased phospho-PP2A level (i.e. inactivated it) in $\mathrm{HG}$ at 1,800 pmol/1 PDGF-BB. PLC $\gamma$ and PTP1B inhibition had only a marginal effect on phospho-PP2A under these conditions.

To confirm that the increased $\mathrm{PKC} \beta_{\mathrm{II}}$ activity brought about by $\mathrm{HG}$ regulates $\mathrm{PP} 2 \mathrm{~A}$ activity, an activity assay was undertaken (Fig. 6g). PKC $\beta_{\mathrm{II}}$ or AR inhibition significantly decreased PP2A activity in 1,800 pmol/l PDGF-BB in $\mathrm{HG}$ conditions while having no significant effect in 360 pmol/1 PDGF-BB.

The present results indicate that as PDGF-BB level increases in $\mathrm{HG}, \mathrm{PKC} \beta_{\mathrm{II}}$ activates $\mathrm{PP} 2 \mathrm{~A}$, thereby reducing 
Fig. 6 Effect of inhibitors on PP2A phosphorylation (inactivation). a Relative densitometric results for phospho-PP2A ${ }^{\text {(Tyr307) }}$ (mean \pm SEM) and respective blot (b), in immunoblotted lysates of cells previously treated as in Fig. $1(n=30$ independent experiments). Loading control: total ERK protein. c-f Results (phosphoPP $2 \mathrm{~A}^{(\mathrm{Tyr} 307)}$ ) for lysates from cells treated as $\mathbf{a}, \mathbf{b}$ plus with inhibitors $(n=8$ independent experiments). g Confirmatory PP2A activity results for inhibitors that significantly increased phospho-PP2A $\mathrm{A}^{\text {(Tyr307) }}(\mathbf{e}, \mathbf{f})$ ( $n=6$ independent experiments). Inhibitors: see legends Figs 2 and 4. Grey squares/grey line, $\mathrm{NG}$; black triangles/continuous line, HG; black circles/dotted line, $\mathrm{NG}+20 \mathrm{mmol} / 1 \mathrm{~L}$-glucose (LG). Grey bars, NG; black bars, HG. Analysis: ANOVA. ${ }^{*} p<0.05$ and $* * p<0.01$ vs basal (B); ${ }^{\dagger} p<0.05$ and ${ }^{\dagger \dagger} p<0.01$ vs NG; ${ }^{*} p<0.05$ and ${ }^{*+} p<0.01$ vs solvent at same glucose level and PDGF-BB concentration

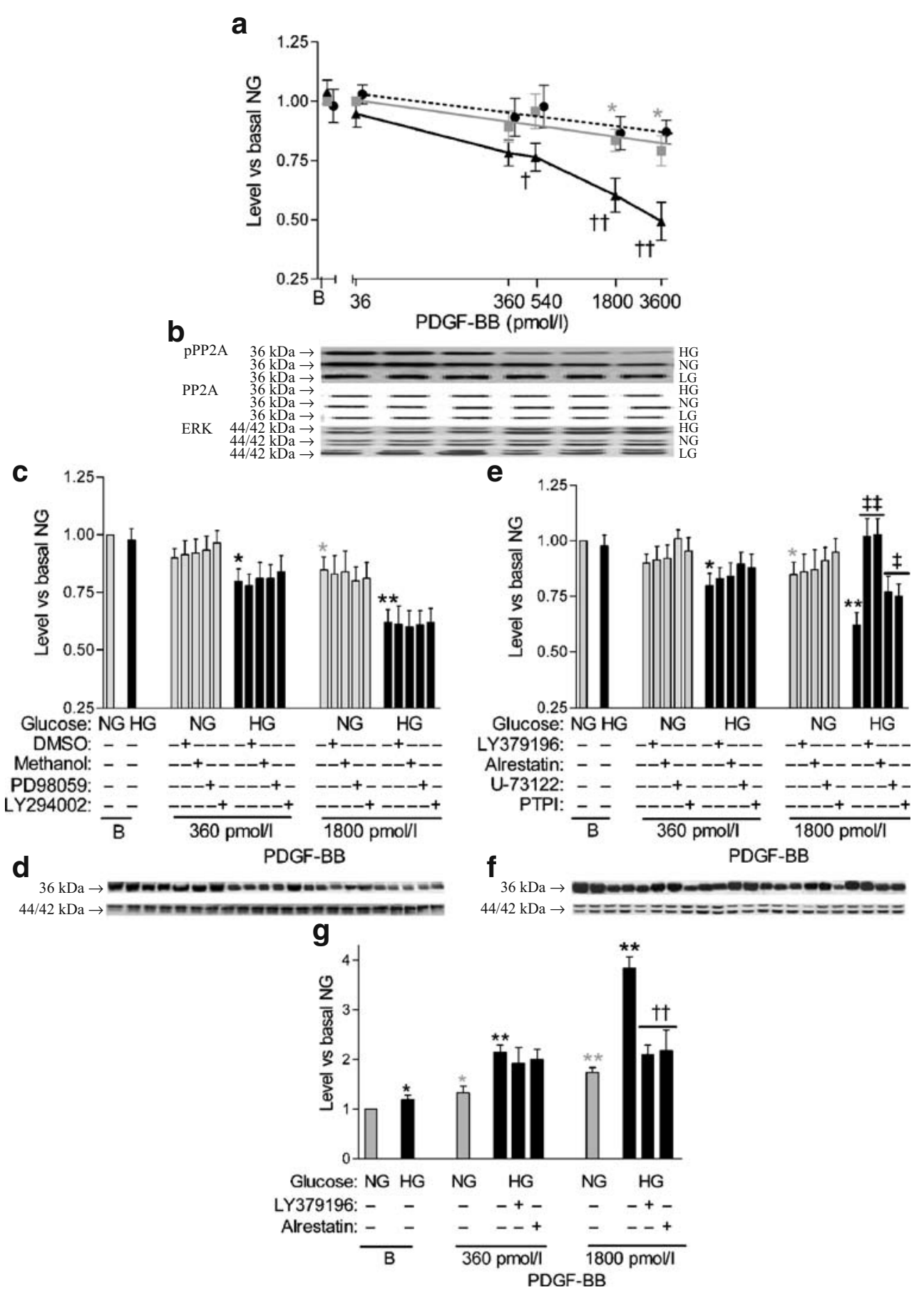

a

P2A

RK

PDGF- $\beta \mathrm{R}$ level and chemotaxis depend on signalling through PI3K/Akt to the MAPK/ERK pathway in response to low PDGF-BB concentrations [7, 8, 11]. In the present work Akt and ERK activation followed similar biphasic changes to those that occurred with receptor expression/ production and chemotaxis.

Atherosclerosis, which critically involves VSMC migration into the growth factor-rich plaque, occurs prematurely in individuals with diabetes. Ambient glucose concentration has a major influence on responses to PDGF-BB. VSMC
BB exists for both PDGF- $\beta$ R expression and chemotaxis in human aortic VSMC. We demonstrated previously that 


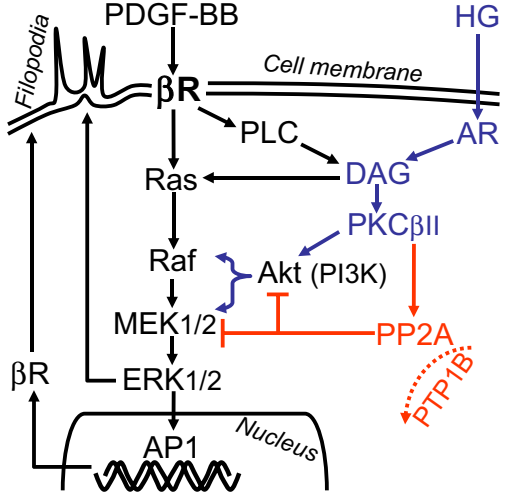

Fig. 7 DAG-dependent pathways activated in aortic VSMC by PDGF-BB and HG. In NG, PDGF-BB signals through the PDGF$\beta R$ kinase to activate the MAPK/ERK pathway encouraging formation of direction-sensing filopodia and upregulating PDGF- $\beta R$. As PDGF-BB concentration increases, VSMC migration, a key factor in atheroma formation, occurs. However, as PDGF-BB increases further, phosphatases, including PTP1B, become activated inhibiting these responses (not shown). In raised glucose conditions, a consistent finding in diabetes, the $\mathrm{DAG} / \mathrm{PKC} \beta_{\mathrm{II}} / \mathrm{PI} 3 \mathrm{~K}$ pathway and DAG/MAPK pathway both lead to ERK activation and migration. We have previously shown that Akt activates the MAPK pathway under these conditions [7], but the point between Ras and ERK1/2 where this occurs has not been demonstrated. Glucose lowers the threshold for migration to PDGF-BB to occur, indicating that even minor vessel wall injuries that release PDGF-BB may more readily trigger atheroma formation. Atherosclerosis is already known to have a premature onset in individuals with diabetes. If, in addition to elevations in glucose level, the PDGF-BB level is increased, PP2A becomes activated in a $\mathrm{PKC} \beta_{\mathrm{II}}$-dependent pathway inhibiting ERK and Akt activation. Decreases in ERK activation are associated with lack of filopodia formation, reduced cellular migration and lower transcriptional regulation of the PDGF- $\beta$ R. PTP1B has a minor role in activating PP2A in conditions of raised glucose and PDGF-BB. Therapies that indirectly target PP2A under conditions of elevated glucose and elevated PDGF-BB may remove a critical inhibitory effect on ERKdependent events and risk potentiating VSMC migration AP-1, activator protein 1

showed no net migration to low PDGF-BB concentrations in $\mathrm{NG}$, but in raised glucose $(>10 \mathrm{mmol} / \mathrm{l})$ migration surpassed that in NG for all PDGF-BB concentrations $\leq 720 \mathrm{pmol} / \mathrm{l}$. Thus, raised glucose levels, a consistent finding in diabetes, may potentiate VSMC migration into growth factor rich plaques.

Arterial tissue alterations in diabetes include increased bone-related molecule production, e.g. osteoprotegerin [31]. Elevated osteoprotegerin levels occur early in atheroma formation and are PDGF-inducible [32, 33]. By potentiating PDGF-induced signalling, hyperglycaemia may encourage arterial alterations associated with atheroma formation. It is likely that even minor vessel wall insults producing small changes in chemoattractant levels can potentiate VSMC migration and significant atheroma formation in individuals with diabetes.

HG caused a left-shift in the biphasic dose response for PDGF- $\beta$ R levels, phospho-Akt and phospho-ERK in re- sponse to PDGF-BB. HG activates PKC $\beta_{\text {II }}$ in VSMC; in these conditions, ERK is stimulated indirectly through the effect of $\mathrm{PKC} \beta_{\text {II }}$ on PI3K/Akt and directly through DAG acting on Ras [8]. The peak phospho-Akt level in HG $(\sim 25 \%$ above that for $\mathrm{NG})$ was only half the difference found for phospho-ERK (peak increase $>50 \%$ ). The greater effect of glucose on MAPK/ERK activity reflects the dual glucose/AR-dependent input to this pathway (Fig. 7). In a previous report on saphenous vein-derived VSMC, PDGF$\mathrm{BB}$ was reported to have a biphasic effect on PDGF- $\beta$ R level and chemotaxis, but the pathways involved were not identified and the ambient glucose level not given [14].

We identified phosphatases that could potentially decrease phospho-ERK in VSMC at high PDGF-BB concentrations. At high PDGF-BB concentrations, both PP2A (a known negative regulator of ERK [34]) inhibition and PTP1B inhibition increased ERK activity and phosphorylation respectively in NG and HG. PTP1B demonstrated a small glucose-independent but PDGF-BB concentrationdependent response. In contrast, combining $\mathrm{HG}$ and high PDGF-BB concentrations greatly increased PP2A activation; this was less marked in NG.

The present results show that $\mathrm{PKC} \beta_{\mathrm{II}}$ activation is independent of the activation status of PP2A, PI3K/Akt and MAPK/ERK; however, PKC $\beta_{\text {II }}$ activates PP2A [35, 36]. In $H G$, when PP2A activity is increased (high PDGF$\mathrm{BB}$ concentrations), $\mathrm{PKC} \beta_{\mathrm{II}}$ inhibition resulted in $\mathrm{PP} 2 \mathrm{~A}$ inactivation and so increased Akt and ERK activation. Thus when both glucose and PDGF-BB are high, $\mathrm{PKC} \beta_{\mathrm{II}}$ activates PP2A, which in turn leads to dephosphorylation of Akt and ERK as well as loss of chemotaxis. It is clear that PDGF-BB cannot cause VSMC chemotaxis when ERK phosphorylation/activation is low from whatever cause.

Increased polyol pathway flux in hyperglycaemia alters intracellular signalling and VSMC migration. The clinical use of AR inhibitors to reduce the vascular complications of diabetes has given disappointing results, perhaps for several reasons [37]. In the present investigation, $\mathrm{AR} / \mathrm{PKC} \beta_{\mathrm{II}}$ inhibition in HG and high PDGF-BB levels actually caused, rather than preventing chemotaxis. Since HG levels and supraphysiological PDGF-BB levels co-exist, in the area of the atheromatous plaque in diabetes [38], these results point to one mechanism that may help explain the lack of success of AR inhibitors in preventing the vascular complications of diabetes.

In contrast to the outcome with AR inhibitors, statin therapy is effective for cardiovascular disease prevention in diabetes [39]. Their major effect is to reduce cholesterol synthesis. However, we have shown here and previously [7] that statins directly inhibit the MAPK pathway (prevent Ras farnesylation) and VSMC migration at clinically relevant concentrations.

In signalling pathways, the critical balance between phosphorylation and dephosphorylation is altered by glu- 
cose, with implications for VSMC chemotaxis and atheroma formation. If the same chemotactic forces identified in this study are exerted in vivo, VSMC may be attracted into the atheromatous plaque at lower concentrations of PDGF$\mathrm{BB}$ in the presence of raised glucose concentrations; this points to another mechanism by which atheroma formation may be accelerated in diabetes.

Acknowledgements This study was supported by a project grant from the Research and Development Office, Department of Health, Social Services, and Public Safety, Northern Ireland.

Duality of interest The authors declare that there is no duality of interest associated with this manuscript.

\section{References}

1. Beckman JA, Creager MA, Libby P (2002) Diabetes and atherosclerosis: epidemiology, pathophysiology, and management. JAMA 287:2570-2581

2. Higuchi ML, Gois JM, Reis MM et al (2006) Co-infection ratios versus inflammation, growth factors and progression of early atheromas. APMIS 114:338-344

3. Waltenberger J (1997) Modulation of growth factor action: implications for the treatment of cardiovascular diseases. Circulation 96:4083-4094

4. Kawano M, Koshikawa T, Kanzaki T, Morisaki N, Saito Y, Yoshida S (1993) Diabetes mellitus induces accelerated growth of aortic smooth muscle cells: association with overexpression of PDGF beta-receptors. Eur J Clin Invest 23:84-90

5. Lev-Ran A, Hwang DL (1990) Epidermal growth factor and platelet-derived growth factor in blood in diabetes mellitus. Acta Endocrinol (Copenh) 123:326-330

6. Ross R (1993) The pathogenesis of atherosclerosis: a perspective for the 1990s. Nature 362:801-809

7. Campbell M, Allen WE, Sawyer C, Vanhaesebroeck B, Trimble ER (2004) Glucose-potentiated chemotaxis in human vascular smooth muscle is dependent on cross-talk between the PI3K and MAPK signaling pathways. Circ Res 95:380-388

8. Campbell M, Trimble ER (2005) Modification of PI3K- and MAPK-dependent chemotaxis in aortic vascular smooth muscle cells by protein kinase CbII. Circ Res 96:197-206

9. Ramana KV, Friedrich B, Tammali R, West MB, Bhatnagar A, Srivastava SK (2005) Requirement of aldose reductase for the hyperglycemic activation of protein kinase $\mathrm{C}$ and formation of diacylglycerol in vascular smooth muscle cells. Diabetes 54:818-829

10. Ballagi AE, Ishizaki A, Nehlin JO, Funa K (1995) Isolation and characterization of the mouse PDGF beta-receptor promoter. Biochem Biophys Res Commun 210:165-173

11. Campbell M, Allen WE, Silversides JA, Trimble ER (2003) Glucose-induced phosphatidylinositol 3-kinase and mitogenactivated protein kinase-dependent upregulation of the plateletderived growth factor-beta receptor potentiates vascular smooth muscle cell chemotaxis. Diabetes 52:519-526

12. Heldin CH, Westermark B (1999) Mechanism of action and in vivo role of platelet-derived growth factor. Physiol Rev 79:1283-1316

13. Barrett TB, Benditt EP (1987) sis (platelet-derived growth factor $\mathrm{B}$ chain) gene transcript levels are elevated in human atherosclerotic lesions compared to normal artery. Proc Natl Acad Sci U S A 84:1099-1103
14. Clunn GF, Refson JS, Lymn JS, Hughes AD (1997) Plateletderived growth factor beta-receptors can both promote and inhibit chemotaxis in human vascular smooth muscle cells. Arterioscler Thromb Vasc Biol 17:2622-2629

15. Knapp J, Aleth S, Balzer F, Schmitz W, Neumann J (2002) Calcium-independent activation of the contractile apparatus in smooth muscle of mouse aorta by protein phosphatase inhibition. Naunyn Schmiedebergs Arch Pharmacol 366:562-569

16. Millward TA, Zolnierowicz S, Hemmings BA (1999) Regulation of protein kinase cascades by protein phosphatase $2 \mathrm{~A}$. Trends Biochem Sci 24:186-191

17. Sharpe PC, Yue KK, Catherwood MA, McMaster D, Trimble ER (1998) The effects of glucose-induced oxidative stress on growth and extracellular matrix gene expression of vascular smooth muscle cells. Diabetologia 41:1210-1219

18. Tanimoto T, Lungu AO, Berk BC (2004) Sphingosine 1-phosphate transactivates the platelet-derived growth factor beta receptor and epidermal growth factor receptor in vascular smooth muscle cells. Circ Res 94:1050-1058

19. Natarajan V, Scribner WM, Hart CM, Parthasarathy S (1995) Oxidized low density lipoprotein-mediated activation of phospholipase D in smooth muscle cells: a possible role in cell proliferation and atherogenesis. J Lipid Res 36:2005-2016

20. Cho HM, Choi SH, Hwang KC et al (2005) The Src/PLC/PKC/ MEK/ERK signaling pathway is involved in aortic smooth muscle cell proliferation induced by glycated LDL. Mol Cells 19:60-66

21. Richter A, Davies DE, Alexander P (1995) Growth inhibitory effects of FK506 and cyclosporin A independent of inhibition of calcineurin. Biochem Pharmacol 49:367-373

22. Mahadevan VS, Campbell M, McKeown PP, Bayraktutan U (2006) Internal mammary artery smooth muscle cells resist migration and possess high antioxidant capacity. Cardiovasc Res 72:60-68

23. Hughes AD, Clunn GF, Refson J, Demoliou-Mason C (1996) Platelet-derived growth factor (PDGF): actions and mechanisms in vascular smooth muscle. Gen Pharmacol 27:1079-1089

24. Sjolund M, Rahm M, Claesson Welsh L, Sejersen T, Heldin CH, Thyberg J (1990) Expression of PDGF alpha- and beta-receptors in rat arterial smooth muscle cells is phenotype and growth state dependent. Growth Factors 3:191-203

25. Webb SE, Pollard JW, Jones GE (1996) Direct observation and quantification of macrophage chemoattraction to the growth factor CSF-1. J Cell Sci 109:793-803

26. Funa K, Uramoto H (2003) Regulatory mechanisms for the expression and activity of platelet-derived growth factor receptor. Acta Biochim Pol 50:647-658

27. Dardik A, Yamashita A, Aziz F, Asada H, Sumpio BE (2005) Shear stress-stimulated endothelial cells induce smooth muscle cell chemotaxis via platelet-derived growth factor-BB and interleukin-1alpha. J Vasc Surg 41:321-331

28. Haj FG, Markova B, Klaman LD, Bohmer FD, Neel BG (2003) Regulation of receptor tyrosine kinase signaling by protein tyrosine phosphatase-1B. J Biol Chem 278:739-744

29. Takehara N, Kawabe J, Aizawa Y, Hasebe N, Kikuchi K (2000) High glucose attenuates insulin-induced mitogen-activated protein kinase phosphatase-1 (MKP-1) expression in vascular smooth muscle cells. Biochim Biophys Acta 1497:244-252

30. Chen J, Parsons S, Brautigan DL (1994) Tyrosine phosphorylation of protein phosphatase $2 \mathrm{~A}$ in response to growth stimulation and v-src transformation of fibroblasts. J Biol Chem 269:79577962

31. Vattikuti R, Towler DA (2004) Osteogenic regulation of vascular calcification: an early perspective. Am J Physiol 286:E686E696

32. Zhang J, Fu M, Myles D et al (2002) PDGF induces osteoprotegerin expression in vascular smooth muscle cells by multiple signal pathways. FEBS Lett 521:180-184 
33. Dhore CR, Cleutjens JP, Lutgens E et al (2001) Differential expression of bone matrix regulatory proteins in human atherosclerotic plaques. Arterioscler Thromb Vasc Biol 21:1998-2003

34. Zhou B, Wang ZX, Zhao Y, Brautigan DL, Zhang ZY (2002) The specificity of extracellular signal-regulated kinase 2 dephosphorylation by protein phosphatases. J Biol Chem 277:31818-31825

35. Huang W, Batra S, Atkins BA, Mishra V, Mehta KD (2005) Increases in intracellular calcium dephosphorylate histone $\mathrm{H} 3$ at serine 10 in human hepatoma cells: potential role of protein phosphatase 2Aprotein kinase CbetaII complex. J Cell Physiol 205:37-46

36. Michell BJ, Chen Z, Tiganis T et al (2001) Coordinated control of endothelial nitric-oxide synthase phosphorylation by protein kinase $\mathrm{C}$ and the cAMP-dependent protein kinase. $\mathrm{J}$ Biol Chem 276:17625-17628

37. Chung SS, Chung SK (2003) Genetic analysis of aldose reductase in diabetic complications. Curr Med Chem 10:1375-1387

38. Haller H, Drab M, Luft FC (1996) The role of hyperglycemia and hyperinsulinemia in the pathogenesis of diabetic angiopathy. Clin Nephrol 46:246-255

39. Colhoun HM, Betteridge DJ, Durrington PN et al (2004) Primary prevention of cardiovascular disease with atorvastatin in type 2 diabetes in the Collaborative Atorvastatin Diabetes Study (CARDS): multicentre randomised placebo-controlled trial. Lancet 364:685-696 